\title{
Ossicular Involvement and Types of Pathology in Chronic Otitis Media Squa-
}

\section{mous Active Disease}

\section{Sharma Swasti ${ }^{1}$}

\section{${ }^{1}$ Corresponding Author:}

Dr Swasti Sharma

Consultant ENT Surgeon,

Department of ENT,

Pokhara Academy of Health Sciences, Western Regional Hospital, Pokhara

E-mail: swastipoudel@yahoo.com

Article received : February 19, 2018

Article accepted : March 13, 2018

\begin{abstract}
Background: Chronic otitis media (COM) squamous type is commonly associated with cholesteatoma. In COM squamous type with active disease, there is retraction of pars flaccida or pars tensa with retention of squamous epithelial debris and is associated with inflammation and production of pus. It is potentially dangerous because it can cause resorption of bone, leading to ossicular erosion and destruction of bony plates of middle ear. The objective of this study is to determine the effect of chronic otitis media squamous type on the ossicular chain as well as to observe the types of pathology in this disease. Methods and materials: Fifty cases of chronic otitis media squamous type who underwent surgical management were included. The status of ossicular chain was evaluated intraoperatively. The type of pathology involving middle ear was also studied. Cases admitted for revision surgery were excluded from the study. Results: Of the total fifty cases, ossicular changes were observed in forty eight cases and in two cases all ossicles were intact. Long process of incus is the most frequently involved ossicle. The most common pathology was found to be mixed type (52\%). Conclusion: The conclusion of this study is that ossicular chain is commonly involved in chronic otitis media squamous type and mixed pathology consisting of cholesteatoma and granulation tissue is the most frequent pathology.
\end{abstract}

Keywords: Cholesteatoma, ossicles, granulations

\section{INTRODUCTION}

Chronic otitis media (COM) squamous type is commonly associated with cholesteatoma. It is divided into active and inactive subtypes. In chronic otitis media squamous type with active disease, there is retraction of pars flaccida or pars tensa which has retained squamous epithelial debris and is associated with inflammation and production of pus. ${ }^{1,2}$ Cholesteatoma is defined as squamous epithelium lined pocket containing keratinous debris trapped within tympanomastoid compartment. It is potentially dangerous because it can cause resorption of bone leading to ossicular erosion, destruction of bony plates of middle ear exposing dura/sinus and erosion of facial canal leading to facial nerve paralysis. This can result in various intratemporal and intracranial complications. So it is known as unsafe or dangerous type of chronic otitis media. ${ }^{3,4}$ Cholesteatoma has to be managed with surgery where the disease from middle ear is removed; middle ear cavity is converted into a single cavity, exteriorized into external auditory canal with preservation of hearing mechanism. This procedure is known as 'modified radical mastoidectomy', which is a type of canal wall down mastoidectomy. Following surgery, patients are asked for periodic follow-up during which the ear is examined and any debris collected in the ear cavity is cleaned. ${ }^{5,-8}$ Pathology of COM includes formation of cholesteatoma or granulation tissues in middle ear cleft. In studies of pathology of COM, it has been shown that cholesteatomas expand with accumulation of desquamated keratin debris which invades adjacent tympanomastoid compartments and ossicles. There is elaboration of various enzymes such as collagenase, elastase, phosphatase and hyaluronidase. Action of these enzymes and pressure from cholesteatoma mass leads to bone erosion which in turn leads to various complications in cholesteatoma. Inflammation within the sac along with infection leads to granulation tissue formation. Granulation tissue appears as pink and granular lesions that are soft. Pathologically, granulation tissue forms due to proliferation of vascular tissue and fibroblast in areas of ongoing inflammation. ${ }^{3}$

\section{METHODS AND MATERIALS}

This is an observational type of study. It was conducted over a period of a year from November 2013 to October 2014 at Department of ENT-HNS, Bir Hospital. Cases of 
COM squamous active were enrolled in the study. Diagnosed cases of COM squamous type who underwent surgery were included. Those cases requiring revision surgery were excluded. Fifty consecutive cases were included in the study. All patients underwent modified radical mastoidectomy. Intraoperative findings were noted. The type of pathology was observed-whether cholesteatoma, granulation tissue or mixed type of pathology. The ossicular chain was examined for the extent of erosion. All the data was processed using SPSS version 20.0 (SPSS, Chicago, IL, USA).

\section{RESULTS}

Maximum number of patients fell in age group 11-20 years. There were twenty three patients in this age group, which constitutes $46 \%$ of all patients. The second most common age group was 21-30 years, which accounted for $40 \%$ of cases. Three patients were categorized in each of the age groups $<10$ and $31-40$ years, which make up $6 \%$ of total. 41-50 years age group had the least number of patients that is one (2\%). Thirty seven patients were male while the rest thirteen were female. Most commonly observed pathology was of mixed type in twenty six cases (52\%). Mixed type pathology included presence of both cholesteatoma and granulation tissue( Table 1). The next common pathology was presence of granulation tissue only in eighteen cases (36\%). The least common pathology was the presence of cholesteatoma only, found in six cases (12\%). Overall, the most common ossicular pathology was erosion of long process of incus. Other common finding was erosion of long process of incus in combination with eroded handle of malleus. Next, absent malleus, incus and stapes suprastructure with just footplate being intact was observed as the third most common ossicular involvement pattern. Of the total fifty cases, ossicular changes were observed in forty eight cases and in two cases all ossicles were intact. The most commonly involved ossicle, as discussed above was incus, followed by malleus and stapes.

\section{Types of Pathology in COM Squamous}

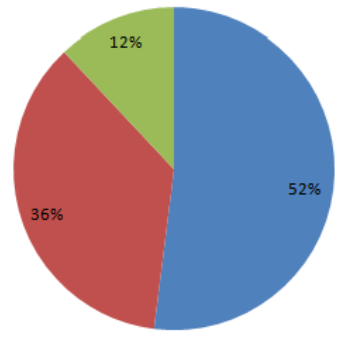

Mixed

- Granulation tissue = Cholesteatoma

Figure1. Types of pathology in COM squamous

\section{DISCUSSION}

In the present study, the most common pathology was found to be mixed (52\%), followed by granulation tissue $(36 \%)$ and cholesteatoma (12\%). ${ }^{9}$ One of the observational study demonstrated that cholesteatoma with granulation was present in $72 \%$, granulation tissue in 16 $\%$ and cholesteatoma in $12 \%$. Involvement of tympanic and mastoid cavities was seen in majority of cases. These observations are similar to those in the current study, except that the frequency of mixed pathology is much higher in their study. ${ }^{9}$ These findings are also similar to those elucidated by another study. They demonstrated that specific pathology was seen in $73.7 \%$ of patients studied. Mixed pathology of cholesteatoma and granulation was detected in $38.1 \%$, cholesteatoma in $18.7 \%$ and granulation in $7.6 \%$. Polyp was found in $9.3 \%$ of patients. The commonest site of pathology was posterior superior quadrant, followed by attic and external auditory canal. ${ }^{10}$ Kumar RV et al demonstrated that 15 cases (30\%) during surgery were found to have granulations only, 15 cases (30\%) were found to have a combination of granulation and cholesteatoma while 20 patients (40\%) had cholesteatoma only. ${ }^{11}$

Ossicles were found to be involved in forty eight cases out of fifty patients. The most commonly involved one was incus (94\%), followed by malleus (54\%) and stapes (34\%). A number of combinations of ossicular involvement were observed. Incus was the most commonly involved ossicle. It was found to be diseased in forty seven cases $(94 \%)$. The most common lesion was erosion of long process of incus in $48 \%$. Incus was totally missing in $18 \%$. Long process was completely absent in 16 $\%$. Other less common lesions were erosion of lenticular process in $8 \%$ and absent long and short process in $4 \%$. In three cases, incus was found to be intact (6\%).Malleus was found to be involved in twenty seven cases (54\%). The most common involvement of malleus was totally absent malleus in $24 \%$ of the twenty seven cases. In 18 $\%$ handle of malleus was eroded, while in $6 \%$ handle of malleus was totally absent. Head of malleus was completely absent in $4 \%$ and it was just eroded in $2 \%$. Malleus was intact in twenty three cases (46\%). Stapes was involved in seventeen cases (34\%). In $30 \%$, stapes suprastructure was absent, while in $4 \%$ head of stapes was missing. Erosion of long process only was present in $28 \%$ of cases. Erosion of long process of incus in combination with erosion of handle of malleus was observed in $14 \%$, which was the second most common pattern of ossicular chain involvement next to erosion of long process. In 10 $\%$ cases, all the ossicles were absent with only the footplate of stapes remaining. In $8 \%$ of cases, the long process of incus and stapes suprastructure were absent, other ossicular remnants being intact. Other combinations of 
ossicular involvement were: absence of malleus and long process of incus; absence of incus and malleus; absence of head of malleus and incus; absence of handle of malleus, long process and stapes head; absence of handle of malleus, long process of incus and stapes suprastructure; erosion of incus, stapes suprastructure and handle of malleus. Each of these combinations was observed in $4 \%$ of cases. In addition, erosion of lenticular process only was observed in $6 \%$ cases. Less common patterns of involvement seen were: erosion of long process and lenticular process; absence of head of malleus and incus; absence of malleus, short process and long process; erosion of lenticular process and stapes crurae; all of ossicles absent except part of incus and footplate. Each of these findings was observed in $2 \%$ of cases. Lastly, all of the ossicles were found to be intact in $2 \%$.

Resorption of bone is a feature of active squamous chronic otitis media. It has been discussed in literature that ossicular involvement in chronic otitis media squamous type is due to a number of causes. One is pressure effect from the accumulated epithelial debris. Another is elaboration of various enzymes from cholesteatoma mass, such as elastase, collagenase, phospholipase etc. Release of inflammatory mediators such as cytokines, interleukins, tumour necrosis factor, prostaglandin, nitric oxide and activation of osteoclasts are important factors. Activated osteoclasts then lead to bone resorption. Resorption of part or whole of ossicles ('resorptive osteitis') is seen in chronic otitis media squamous type as well as mucosal type. The affected ossicles show hyperemia with proliferation of capillaries and prominent histiocytes. Long process of incus is particularly susceptible because of its delicate structure rather than its tenuous blood supply. ${ }^{12-17}$

Albera $\mathrm{R}$ et al noted ossicular changes in $82 \%$ of hundred and forty patients. Incus was involved in $78 \%$, malleus in $20 \%$ and stapes in $29 \%$. In $45 \%$ more than one ossicle was involved. ${ }^{18}$ Salman AA et al reported that the two most common patterns of involvement were erosion of long process of incus and stapes supra-structure. 97 $\%$ cases showed ossicular defects while in the rest $3 \%$ ossicles were intact. ${ }^{19}$ Mohammadi $\mathrm{G}$ et al observed that ossicles were affected in $94.5 \%$ of hundred and sixty six patients. Incus was involved in $86.1 \%$, stapes in 66.8 $\%$ and malleus in $43.9 \%$. Most widely damaged part of incus was its long process followed by its body. Erosion of stapes superstructure was more common than total loss of bone. Damage to malleus was the least common finding, while intact ossicular chain was observed in only nine patients. The most common combination of erosion of ossicles was damage to all ossicles except footplate. Next most common combination of damage was concur- rent damage to incus and superstructure. Partial damage of malleus and superstructure of stapes with complete destruction of incus was the third most common combination of damage. They concluded that widespread cholesteatoma results in greater ossicular erosion and poor hearing outcomes. They discussed that patients suffering from damage to all three ossicles had extensive cholesteatoma in tympanic cavity, mastoid, attic and antrum. Most patients who had involvement of multiple ossicles had significant cholesteatoma inside the tympanic cavity such that $85 \%$ of patients with damage to the incus and stapes showed cholesteatoma of the sinus tympani, oval window, facial recess and round window. ${ }^{20}$ Shrestha $\mathrm{S}$ et al described that malleus involvement by cholesteatoma was noted in majority of cases. Incus was noted to be eroded in twenty eight patients $(56 \%)$ and erosion of stapes superstructure was seen in twelve patients $(24 \%){ }^{9}$

\section{CONCLUSION:}

The most common pathology in this study was found to be mixed (consisting of both granulations and cholesteatoma.Incus was observed to be the most frequently involved ossicle.

\section{REFERENCES}

1. Browning GG, Merchant SN, Kelly G, Swan IRC, Canter R, Mckerrow WS. Chronic otitis media. In: Gleeson M. Scott-Brown's otorhinolaryngology, head and neck surgery. 7th ed. London: Hodder Arnold; 2008. p. 3410.

2. Dhingra PL. Cholesteatoma and chronic suppurative otitis media. In: Dhingra PL. Diseases of ear, nose and throat. 4th ed. New Delhi: Elsevier; 2007. p. 66-72.

3. Slaterry WH. Pathology and clinical course of inflammatory diseases of middle ear. In: Glasscock ME, Gulya AJ. Glasscock-Shambaugh Surgery of the ear. 5th ed. New Delhi: Elsevier; 2003:429.

4. Browning GG, Merchant SN, Kelly G, Swan IRC, Canter R, Mckerrow WS. Chronic otitis media. In: Gleeson M. Scott-Brown's otorhinolaryngology, head and neck surgery. 7th ed. London: Hodder Arnold; 2008.p. 3395-434.

5. Mills RP. Management of chronic suppurative otitis media. In: Kerr AG, Booth JB. Scott-Brown's Otolaryngology. 6th ed. Oxford: Butterworth Heinemann; 1997. p. 3/10/1.

6. Evandro J, Alvares N, Negro J. Choleateatoma surgery in children and adolescents: analysis in 200 patients. International archives of otorhinolaryngology 2006; 10(1).

7. Nikolopoulos TP, Gerbesiotis P. Surgical management of cholesteatoma:the two main options and the third way-atticotomy/ limited masoidectomy. Int J PediatrOtorhinolaryngol 2009; 73(9):1222-7.

8. Kveton JF. Open cavity mastoid operations. In: Glasscock ME,Gulya AJ. Surgery of the ear. 5th ed. New Delhi: Elsevier; 2003.p. 499-15.

9. Shrestha $\mathrm{S}$,Kafle P. Intraoperative findings during canal wall down mastoidectomy in children. Journal of Nepal Paediatric Society $2011 ; 31(3): 184-7$.

10. Chalise SR, Bhandary S. Chronic suppurative otitis media 'unsafe type': an experience at a tertiary care hospital. Nepalese J ENT 
Head Neck Surg 2013; 4(1): 23-5.

11. Kumar RV, Koribipati NK, Krishna RN, Indira S, Ramakrishnan P. Infection and ossicular necrosis in atticoantral disease. Otolaryngology online journal. 2015; 5(1).

12. Semaan MT, Megerian CA. The pathophysiology of cholesteatoma. OtolaryngolClin N Am 2006;39:1143-59.

13. Chole RA, McGinn MD, Tinling SP. Pressure-induced bone resorption in the middle ear Ann OtolRhinolLaryngol 1985;94(2 Pt 1): $165-70$.

14. Burger EH, Klein-Nulen J. Responses of bone cells to biomechanical forces in vitro. Adv Dent Res 1999;13:93-8.

15. Jung JY, Pashia ME, Nishimoto SY, et al. A possible role for nitric oxide in osteoclastogenesis associated with cholesteatoma. OtolNeurotol 2004;25(5):661-8.

16. Yan SD, Huang CC. The role of tumor necrosis factor-alpha in bone resorption of cholesteatoma. Am J Otolaryngol 1991; 12(2):83-9.

17. Klein-Nulend J, van der Plas A, Semeins CM, et al. Sensitivity of osteocytes to biomechanical stress in vitro. FASEB J 1995;9(5):441-5

18. Albera R, Canale A, Piumetto E, Lacilla M, Dagna F. Ossicular chain lesions in cholesteatoma. Acta Otorhinolaryngologica Italica 2012;32:309-13

19. Salman AA, Azhar K, Muhammad EK, Muhammad M. Analytical study of ossicular chain in middle ear cholesteatoma. King Edwards Medical University Annals 2009; 15(3):134-7.

20. Mohammadi G, Naderpour M, Mousaviagdas M. Ossicular erosion in patients requiring surgery for cholesteatoma. Iranian Journal of Otorhinolaryngology 2012; 24(3):125-8. 